\title{
Hubungan Lama Pengobatan dan Jenis Obat Antiepilepsi dengan Derajat Depresi pada Pasien Epilepsi
}

\author{
Meita Nurfitriani Saefulloh, ${ }^{1}$ Ratna Dewi Indi Astuti, ${ }^{2}$ Waya Nurruhyuliawati, ${ }^{3}$ \\ Yuke Andriane, ${ }^{4}$ Miranti Kania Dewi ${ }^{5}$ \\ ${ }^{1}$ Program Studi Pendidikan Dokter, Fakultas Kedokteran Universitas Islam Bandung \\ ${ }^{2}$ Departemen Parasitologi, Fakultas Kedokteran, Universitas Islam Bandung \\ ${ }^{3}$ Departemen Neurologi, RSUD Al-Ihsan Provinsi Jawa Barat \\ 4Departemen Farmakologi, Fakultas Kedokteran, Universita Islam Bandung
}

\begin{abstract}
Abstrak
Epilepsi merupakan kelainan otak kronik yang ditandai dengan kecenderungan terjadi bangkitan epileptik. Terapi epilepsi dilakukan dalam jangka waktu yang lama untuk mengurangi kejadian bangkitan sehingga dapat meningkatkan kemungkinan terjadi efek samping di antaranya depresi. Depresi pada pengobatan epilepsi berhubungan dengan jenis obat antiepilepsi dan lama pengobatan. Penelitian ini bertujuan mengetahui hubungan lama pengobatan dan jenis obat epilepsi dengan derajat depresi pada pasien epilepsi. Metode penelitian ini merupakan observasi analitik dengan rancangan potong lintang. Subjek penelitian adalah 74 pasien epilepsi di Poli Saraf RSUD Al-Ihsan periode Maret-Mei 2018 yang memenuhi kriteria inklusi, yaitu pasien yang sudah meminum obat antiepilepsi generasi pertama monoterapi minimal satu bulan. Sampel dipilih secara purposive sampling dan telah mengisi kuesioner Beck Depression Inventory II. Data penelitian dianalisis dengan uji statistik menggunakan Uji Fischer Exact. Hasil penelitian ini menunjukkan jumlah pasien epilepsi yang mengalami depresi derajat minimal paling banyak ditemukan dan tidak terdapat hubungan lama pengobatan dan jenis obat antiepilepsi dengan derajat depresi pada pasien epilepsi. Kejadian depresi pada pasien epilepsi selain dipengaruhi jenis obat dan lama pengobatan juga dipengaruhi oleh keadaan epilepsi (frekuensi kejang dan jenis epilepsi), faktor iatrogenik (obat antiepilepsi), dan faktor psikososial.
\end{abstract}

Kata kunci: depresi, epilepsi, lama pengobatan, obat antiepilepsi

\section{Association of Duration Medication and Types of Anti Epileptic Drugs with Degree of Depression in Patient with Epilepsy}

\begin{abstract}
Epilepsy is a chronic disorder of brain which characterized episode of epileptic seizures. Duration treatment of epilepsy is in quite long period to reduce the incidence of seizure, this condition can increase the risk of side effects such as depression. Depression in patients with epilepsy is associated with the type of anti-epilepsy drugs and the duration of treatment. This study was to determine the relationship between the duration of treatment and the type of epilepsy drug with the degree of depression in patients with epilepsy. This research was an analytic observation with cross sectional design. Subjects were 74 epileptic patients in the Nerve Outpatient of Al-Ihsan General Hospital in the period March-May 2018 which met the inclusion criteria who had taken anti epileptic drugs first generation monotherapy for at least 1 month. The sample was chosen by purposive sampling and has filled out the Beck Depression Inventory II questionnaire. Research data were analyzed by statistical test using Fischer Exact test. The results in this study patients with epilepsy who has minimal degree of depression is most common and there was no relationship between treatment duration and type of anti-epileptic drugs with degrees of depression in epilepsy patients. The incidence of depression in patients with epilepsy not only caused by the type of drug and duration of treatment but can also caused by epilepsy condition itself (seizure frequency and type of epilepsy), iatrogenic factors (anti-epileptic drugs) and psychosocial factors.
\end{abstract}

Keywords: anti epileptic drugs, depression, duration of treatment, epilepsy

Korespondensi: Meita Nurfitriani Saefulloh. Program Studi Pendidikan Dokter. Alamat: Jl. Tamansari No.20, Bandung 40116, Provinsi Jawa Barat Telepon: 0224203368 Faksimile: 0224203368 Email: meitachoi@gmail.com. 


\section{Pendahuluan}

Epilepsi termasuk dalam penyakit kronik pada otak yang dapat menyerang semua usia. World Health Organization (WHO) memperkirakan 2,4 juta orang terdiagnosis epilepsi setiap tahunnya. ${ }^{1}$ Epilepsi merupakan kelainan otak yang ditandai kecenderungan terjadi bangkitan epileptik yang menimbulkan konsekuensi neurobiologis, kognitif, dan psikososial. ${ }^{2}$ Sekitar 50\% orang dewasa dengan epilepsi yang aktif memiliki minimal satu gejala komorbid psikiatri. Komorbiditas psikiatrik yang paling sering terjadi pada pasien epilepsi adalah depresi. ${ }^{2}$

Depresi dapat terjadi $3-10$ kali lebih sering pada epilepsi dibanding dengan populasi yang sehat. ${ }^{3}$ Kondisi komorbiditas gangguan depresi memerlukan perhatian lebih karena berisiko mengurangi kualitas hidup dan komplikasi yang mengancam jiwa seperti bunuh diri. ${ }^{4}$

Beberapa etiologi depresi pada epilepsi umumnya berhubungan dengan keadaan epilepsi (frekuensi kejang danjenisepilepsi),faktoriatrogenik(diantaranya obat antiepilepsi dan pembedahan), serta faktor sosial demografi..$^{5,6}$ Obat antiepilepsi (OAE) dapat memicu berbagai masalah psikiatrik dengan mekanisme kerja yang spesifik terhadap keadaan epilepsi. Beberapa obat dapat menyebabkan depresi atau gangguan mood dengan cara menghambat aktivitas kanal-kanal ion pada neuron pre maupun post-sinaps seperti kanal ion sesuai dengan mekanisme kerja OAE pada umumnya. Obat antiepilepsi bekerja dengan cara meningkatkan aktivitas dan sintesis neurotransmiter inhibisi GABA sehingga sebagian besar mekanisme obat antiepilepsi dapat menyebabkan gangguan depresi adalah melalui peran GABA-ergik obat tersebut.?

Klasifikasi obat antiepilepsi dapat dibedakan menjadi generasi pertama (lama) dan generasi baru. Di Indonesia, jenis OAE generasi pertama masih banyak digunakan. Obat generasi pertama yang sering digunakan adalah fenobarbital, karbamazepin, fenitoin, dan valproat. ${ }^{8}$ Obat antiepilepsi generasi pertama masih banyak digunakan di Indonesia karena sistem pembiayaan asuransi kesehatan nasional seperti BPJS hanya menjamin obat generasi pertama. ${ }^{9}$

Penelitian mengenai faktor risiko penyebab depresi pada pasien epilepsi oleh Tao dan Wang 5 menunjukkan beberapa obat generasi pertama yang berhubungan dengan depresi adalah fenobarbital dan fenitoin. Berdasar atas durasi pengobatan, penelitian efek neuropsikologis antara obat karbamazepin dan valproat oleh Shehata dkk.11 di Mesir menunjukkan kejadian depresi pada pasien ditentukan oleh durasi penggunaan obat dan jumlah yang diberikan. Berdasar atas uraian tersebut penelitian ini dilakukan untuk mengetahui hubungan lama pengobatan dan jenis OAE yang digunakan pasien dengan derajat depresi epilepsi di Poli Saraf RSUD Al-Ihsan.

\section{Metode}

Penelitian ini menggunakan rancangan metode observatif analitik dengan pendekatan cross sectional. Subjek penelitian dipilih berdasar atas kriteria inklusi, yaitu pasien yang telah menerima pengobatan OAE generasi pertama monoterapi minimal selama 1 bulan dan sebelumnya tidak pernah didiagnosis memiliki gangguan psikologis. Data primer didapatkan dari hasil pengisian kuesioner Beck Depression Inventory II. Penelitian ini dilakukan di Poli Saraf RSUD AlIhsan Bandung pada periode Maret-Mei 2018 dengan jumlah responden sebanyak 74 orang. Analisis data penelitian menggunakan Uji Eksak Fisher untuk menguji hubungan antara variabel dan tipe data kategorik.

Penelitian ini telah mendapat persetujuan etik oleh Komite Etik Penelitian Kesehatan Fakultas Kedokteran Universitas Islam Bandung dengan Nomor: 253/ Komite Etik.FK/III/2O18.

\section{Hasil}

Karakteristik subjek penelitian berdasar atas lama pengobatan dan jenis obat antiepilepsi generasi pertama pasien epilepsi di RSUD Al-Ihsan dapat dilihat pada Tabel 1.

Tabel 1 Karakteristik Pasien Epilepsi berdasar atas Lama Pengobatan dan Jenis Obat Antiepilepsi Generasi Pertama yang Digunakan

\begin{tabular}{lcc}
\hline Karakteristik Responden & $\mathbf{n = 7 4}$ & $\mathbf{\%}$ \\
\hline Lama pengobatan (bulan) & & \\
$\quad 1-12$ & 21 & 28 \\
$\geq 12$ & 53 & 72 \\
Jenis OAE generasi pertama & & \\
$\quad$ Fenobarbital & 4 & 5 \\
Karbamazepin & 9 & 12 \\
Fenitoin & 34 & 46 \\
Valproat & 27 & 37 \\
\hline
\end{tabular}

Sebagian besar pasien epilepsi di Poli Saraf RSUD ALIhsan Bandung (72\%) telah menerima pengobatan $\geq 12$ bulan. Jenis obat antiepilepsi generasi pertama yang paling banyak digunakan secara berurutan adalah fenitoin, valproat, karbamazepin, dan fenobarbital (Tabel 1).

Tabel 2 Gambaran Derajat Depresi pada Pasien Epilepsi di RSUD Al-Ihsan

\begin{tabular}{lcc}
\hline Derajat Depresi & $\mathbf{n = 7 4}$ & \% \\
\hline Minimal & 39 & 52 \\
Ringan & 11 & 15 \\
Sedang & 18 & 24 \\
Berat & 6 & 8 \\
\hline
\end{tabular}

Sebagian besar pasien epilepsi (53\%) memiliki derajat depresi minimal atau tanpa depresi. Jumlah pasien epilepsi yang mengalami depresi derajat ringan, sedang, dan berat jumlahnya hampir sama besar dengan pasien yang mengalami depresi minimal (tanpa depresi; Tabel 2). 
Hasil hubungan antara lama pengobatan dengan derajat depresi pada pasien epilepsi di RSUD Al-Ihsan periode Maret-Mei 2018 dijelaskan dalam Tabel 3.

Pasien yang telah menjalani pengobatan selama 1-12 bulan, jumlah pasien yang mengalami depresi sebanyak 10 orang dan yang mengalami depresi minimal atau tanpa depresi sebanyak 11 orang. Demikian pula pada pasien yang menerima pengobatan $\geq 12$ bulan sebanyak 25 orang mengalami depresi dan sebanyak 28 orang mengalami depresi minimal (tanpa depresi; Tabel 3).

Pada kedua kelompok lama pengobatan, derajat depresi yang paling banyak dialami 6 orang adalah derajat sedang, lama pengobatan 1-12 bulan, dan sebesar $12 \%$ pada kelompok lama pengobatan $\geq 12$ bulan. Jumlah pasien yang mengalami depresi tidak menunjukkan perbedaan batas pengobatan 1-12 bulan dan $\geq 12$ bulan (Tabel 3 ). depresi paling banyak ditemukan. Pada pasien yang telah menjalani pengobatan selama 1-12 bulan, jumlah pasien yang mengalami depresi dan mengalami depresi minimal atau tanpa depresi jumlahnya hampir sama besar. Demikian pula dengan pasien yang menerima pengobatan $\geq 12$ bulan jumlah pasien yang mengalami depresi hampir sama besar dengan yang mengalami depresi minimal (tanpa depresi). Pada penelitian ini jumlah pasien yang mengalami depresi sekitar 47\%, sedangkan yang mengalami depresi minimal atau tanpa depresi sebanyak 53\%.

Hasil ini sejalan dengan penelitian yang dilakukan oleh Wiglusz dkk. ${ }^{10}$ pasien yang telah menerima pengobatan selama 1 tahun sebanyak $42 \%$ telah menunjukkan gejala depresi. Akan tetapi, hasil ini tidak sesuai dengan penelitian Shehata dkk. ${ }^{11}$ menunjukkan hubungan durasi konsumsi obat antiepilepsi dengan skor depresi.

Tabel 3 Hubungan Lama Pengobatan dengan Derajat Depresi

\begin{tabular}{|c|c|c|c|c|c|}
\hline \multirow[b]{2}{*}{$\begin{array}{c}\text { Lama Pengobatan } \\
\text { (Bulan) }\end{array}$} & \multicolumn{4}{|c|}{ Derajat Depresi } & \multirow{2}{*}{$\begin{array}{c}\text { Nilai } \\
\text { p }^{*}\end{array}$} \\
\hline & $\begin{array}{l}\text { Minimal } \\
\mathbf{n = 3 9}\end{array}$ & $\begin{array}{c}\begin{array}{c}\text { Ringan } \\
n=11\end{array} \\
\end{array}$ & $\begin{array}{c}\text { Sedang } \\
n=18\end{array}$ & $\begin{array}{c}\text { Berat } \\
n=6\end{array}$ & \\
\hline $1-12$ & 11 & 2 & 6 & 2 & 0,88 \\
\hline$\geq 12$ & 28 & 9 & 12 & 4 & \\
\hline
\end{tabular}

*Uji Eksak Fisher

Tabel 4 Hubungan Jenis Obat Antiepilepsi Generasi Pertama dengan Derajat Depresi

\begin{tabular}{|c|c|c|c|c|c|}
\hline \multirow[b]{2}{*}{$\begin{array}{c}\text { Jenis OAE Generasi } \\
\text { Pertama }\end{array}$} & \multicolumn{4}{|c|}{ Derajat Depresi } & \multirow[b]{2}{*}{ Nilai $p^{*}$} \\
\hline & $\begin{array}{l}\text { Minimal } \\
\qquad n=\mathbf{3 6}\end{array}$ & $\begin{array}{c}\text { Ringan } \\
\mathbf{n}=11\end{array}$ & $\begin{array}{c}\text { Sedang } \\
n=18\end{array}$ & $\begin{array}{c}\text { Berat } \\
n=6\end{array}$ & \\
\hline Fenobarbital & 2 & 1 & 1 & $\mathrm{O}$ & \multirow{4}{*}{0,62} \\
\hline Karbamazepin & 5 & 2 & $\mathrm{O}$ & 2 & \\
\hline Fenitoin & 18 & 5 & 9 & 2 & \\
\hline Valproat & 14 & 3 & 8 & 2 & \\
\hline
\end{tabular}

*Uji Eksak Fisher

Pada semua jenis obat antiepilepsi jumlah pasien epilepsi yang mengalami depresi dan yang menjalani depresi minimal (tanpa depresi) hampir sama.

Di antara keempat jenis obat, pasien yang menggunakan obat karbamazepin mengalami derajat depresi berat paling banyak, sedangkan di antara pasien epilepsi yang mengalami depresi, pasien dengan depresi derajat sedang paling banyak ditemukan, yaitu pada kelompok pengobatan valproat dan fenitoin.

Hasil analisis statistik menggunakan Uji Eksak Fisher menunjukkan nilai $\mathrm{p}=0,62(\mathrm{p}>0,05)$ sehingga dapat disimpulkan tidak terdapat hubungan signifikan antara jenis OAE generasi pertama dan derajat depresi.

\section{Pembahasan}

Subjek yang digunakan pada penelitian ini sejumlah 74 pasien dan telah mengisi kuesioner Beck Depression Inventory II. Pada kedua kelompok berdasar atas lama pengobatan, depresi derajat minimal atau tanpa
Patogenesis depresi akibat pengobatan bersifat multifaktorial. Faktor tersebut di antaranya dosis titrasi yang tinggi, kemampuan obat tersebut untuk menurunkan kadar asam folat, dan potensiasi neurotransmisi GABAergik. Pada keadaan depresi terjadi gangguan fungsi GABA dan juga gangguan neurotransmiter monoamin seperti serotonin, norepinefrin, dan dopamin. Konsumsi OAE dalam jangka waktu lamajuga dapat menyebabkan kadar asam folat yang rendah. Asam folat mempunyai peranan penting pada susunan saraf pusat dan berhubungan dengan metabolisme monoamine. Bilamana kadar neurotransmiter monoamin (serotonin, norepinefrin, dan dopamin) rendah dapat menyebabkan depresi. ${ }^{12,13}$

Hasil pada penelitian ini pasien epilepsi yang mengonsumsi obat durasi $\geq 12$ bulan maupun 1-12 bulan memiliki kemungkinan yang sama untuk mengalami depresi. Keadaan tersebut menyebabkan diperlukan perhatian para klinisi dalam hal followup terapi karena depresi dapat memerparah kejadian epilepsi, memengaruhi kualitas hidup, dan menimbulkan gangguan psikososial bahkan dapat 
menimbulkan ide bunuh diri. ${ }^{4}$ Pada keadaan depresi suasana hati seseorang sangat terganggu oleh perasaan kehilangan, kesedihan, keputusasaan, dan kegagalan. Pada individu yang sangat tertekan, fungsi kognitif seperti perhatian, konsentrasi, dan pemrosesan informasi menurun mengakibatkan banyak bentuk keterbatasan sosial yang mengarah pada penurunan kualitas hidup dan bunuh diri. ${ }^{14}$ Penelitian ini menunjukkan bahwa kejadian depresi derajat minimal paling banyak ditemukan pada pasien epilepsi yang mendapatkan terapi OAE generasi pertama. Hasil uji statistik menunjukkan tidak terdapat hubungan obat antiepilepsi generasi pertama dengan derajat depresi pada pasien epilepsi. Hasil ini tidak sesuai dengan penelitian yang dilakukan oleh Wen dkk.15 bahwa terdapat hubungan penggunaan obat antiepilepsi dengan depresi dan kemungkinan terjadi ide bunuh diri. Penelitian oleh Bosak dkk. ${ }^{16}$ menunjukkan bahwa dari beberapa faktor yang menyebabkan depresi pada pasien epilepsi, jenis obat antiepilepsi generasi pertama tidak menunjukkan nilai signifikasi penyebab depresi.

Pengurangan aktivitas neuronal yang berlebihan dalam jangka waktu yang lama dapat mengganggu kecepatan aktivitas neuronal pada neuron post sinaps yang merupakan efek samping umum pada mekanisme kerja sebagian besar obat antiepilepsi. ${ }^{11}$ Beberapa faktor menunjukkan hubungan antara obat antiepilepsi dan gejala depresi, yaitu peningkatan aktivitas neurotransmiter inhibitor GABAergik karena blokade kanal Na sehingga pada keadaan pasien yang sudah mendapatkan pengobatan antiepilepsi terdapat peningkatan neurotransmiter inhibitorik seperti GABA yang dapat memicu depresi. ${ }^{17}$ Berdasar atas hasil penelitian ini juga didapatkan persentase kejadian depresi hampir sama besar untuk keseluruhan jenis OAE. Akan tetapi, karbamazepin menunjukkan persentase kejadian depresi paling rendah jika dibanding dengan jenis OAE yang lain. Meskipun sebagian besar kejadian depresi pada jenis pengobatan karbamazepin merupakan derajat depresi berat. Hal ini sejalan dengan penelitian yang dilakukan oleh Eddy dkk. ${ }^{18}$ bahwa pada $25 \%$ anak yang mengonsumsi obat karbamazepin terdapat perubahan perilaku seperti depresi. Menurut Harsono ${ }^{19}$, depresi merupakan salah satu efek samping penggunaan obat fenitoin. Penelitian Eddy dkk. ${ }^{18}$ juga menunjukkan bahwa efek samping behavior berupa depresi lebih besar pada pasien yang menggunakan fenitoin dibanding dengan karbamazepin, fenobarbital, valproat, dan primidon.

Obat karbamazepin sudah dikenal sejak awal memiliki efek positif psikotropik. Karbamazepin dapat digunakan sebagai pengobatan pada pasien bipolar karena memiliki struktur kimiawi yang mirip dengan obat tricyclic antidepressant, walaupun efek tersebut akan muncul dalam jangka waktu lebih panjang dibanding dengan obat psikotropik lainnya. ${ }^{20}$ Padajenis obat valproat dan fenitoin terjadi peningkatan respons hiperpolarisasi pada GABA yang akan menghambat aktivitas reseptor NMDA. Efek supresi pada respons sinaptik yang dimediasi oleh reseptor NMDA ini akan memengaruhi gangguan terhadap potensiasi jangka panjang dan depresi jangka panjang. ${ }^{11}$

Penelitian ini memperlihatkan tidak terdapat hubungan yang signifikan antara lama pengobatan dan jenis obat antiepilepsi terhadap depresi. Hal ini kemungkinan terjadi karena faktor lain yang memengaruhi tejadinya depresi. Kejadian depresi pada pasien dengan penyakit epilepsi dapat dipengaruhi oleh faktor lain seperti onset usia kejang, durasi dan frekuensi bangkitan, tipe bangkitan kejang, stress status pekerjaan, status pendidikan, masalah sosial, dan kemampuan diri dalam menangani penyakit kroniknya. ${ }^{10}$ Keadaan komorbid depresi pada pasien epilepsi dapat memengaruhi kualitas hidup pasien dan status kesehatan, stigmastisasi, ataupun ide untuk bunuh diri. ${ }^{21}$

\section{Simpulan}

Simpulan, tidak terdapat hubungan lama pengobatan dan jenis obat antiepilepsi generasi pertama dengan derajat depresi pada pasien epilepsi di RSUD Al-Ihsan periode Maret-Mei 2018.

\section{Ucapan Terima Kasih}

Ucapan terima kasih disampaikan kepada RSUD AlIhsan khususnya Poli Saraf RSUD Al-Ihsan sehingga penelitian ini dapat dilaksanakan.

\section{Daftar Pustaka}

1. WHO | Epilepsy [Internet]. Jenewa: World Health Organization; 2017.

2. Fisher RS, Acevedo C, Arzimanoglou A, Bogacz A, Helen Cross J, Elger CE, dkk. A practical clinical definition of epilepsy. Epilepsia. 2014;55(4):47582.

3. Josephson CB, Jetté N. Psychiatric comorbidities in epilepsy. Int Rev Psychiatry. 2017;29(5):40924.

4. Ekinci O, Titus JB, Rodopman AA, Berkem M, Trevathan E. Depression and anxiety in children and adolescents with epilepsy: Prevalence, risk factors, and treatment. Epilepsy Behav. 2009;14(1):8-18.

5. Tao K, Wang X. The comorbidity of epilepsy and depression: diagnosis and treatment. Expert Rev Neurother. 2016;16(11):1321-33.

6. Mula M, Sander JW. Negative effects of antiepileptic drugs on mood in patients with epilepsy. Drug Saf. 2007;30(7):555-67.

7. Schousboe A, Madsen KK, Barker-Haliski ML, White HS. The GABA synapse as a target for antiepileptic drugs: a historical overview focused on GABA Transporters. Neurochem Res. 2014;39(10):1980-7.

8. Mughni $\mathrm{MH}$, Mahama $\mathrm{CN}$. Profil penyandang epilepsi di Poliklinik Saraf RSUP Prof. Dr. R. D. Kandou Manado. J e-Clinic. 2015;4:1-5.

9. Indonesia MKR. Formularium Nasional 2013. 2013;53(9):12.

10. Wiglusz MS, Landowski J, Michalak L, Cubała WJ. Reevaluating the prevalence and diagnostic subtypes of depressive disorders in epilepsy. 
Epilepsy Behav. 2015;53:15-9.

11. Shehata GA, Bateh AEM, Hamed SA, Rageh TA, Elsorogy YB. Neuropsychological effects of antiepileptic drugs (carbamazepine versus valproate) in adult males with epilepsy. Neuropsychiatr Dis Treat. 2009;5:527-33.

12. Mula M, Monaco F. Antiepileptic drugs and psychopathology of epilepsy: an update. Epileptic Disord. 2009;11(1):1-9.

13. Ropper AH, Samuels MA, Klein J, Prasad S. Adams \& Victor's principles of neurology. Edisi ke-11. Canadian. McGraw Hill Education; 2015.

14. Basak AK, Chatterjee T. Structural and neurochemical alterations in brain regions of depression and suicide patients. Clin Depress. 2016;2(3):1-6.

15. Wen X, Meador KJ, Loring DW, Eisenschenk S, Segal R, Hartzema AG. Is antiepileptic drug use related to depression and suicidal ideation among patients with epilepsy? Epilepsy Behav. 2010;19(3):494-500.

16. Bosak M, Turaj W, Dudek D, Siwek M, Szczudlik A. Depressogenic medications and other risk factors for depression among Polish patients with epilepsy. Neuropsychiatr Dis Treat. 2015 Sep 30;11:2509-17. doi: 10.2147/NDT.S91538. eCollection 2015

17. Sadock BJ, Sadock VA, Ruiz P. Synopsis of psychiatry: behavioral science/ clinical psychiatry. Synopsis of psychiatry: behavioral science/clinical psychiatry. Edisi ke-11. New York: Wolters Kluwer. 2015.

18. Eddy CM, Rickards HE, Cavanna AE. Behavioral adverse effects of antiepileptic drugs in epilepsy. J Clin Psychopharmacol. 2012;32(3):362-75.

19. Harsono. Behavior changes in epilepsy patients. Edisi ke-2. Yogyakarta: Gadjah Mada University Press; 2014.

20. Zhang ZJ, Tan QR, Tong Y, Li Q, Kang WH, Zhen $\mathrm{XC}$, dkk. The effectiveness of carbamazepine in unipolar depression: a double-blind, randomized, placebo-controlled study. J Affect Disord. 2008;109(1-2):91-7.

21. Karouni M, Arulthas S, Larsson PG, Rytter E, Johannessen SI, Landmark CJ.. Psychiatric comorbidity in patients with epilepsy: a population-based study. Eur J Clin Pharmacol. 2010;66(11):1151-6o. 